be resisted by a certain chain, we are using a colloquial and inaccurate expression, like calling a door heavy when we are not attempting the feat of Samson, but merely opening or shutting it, turning it on its well-oiled hinges.

During the present session we have aided ourselves in Glasgow with four very important helps to the teaching of the kinetic system of force-measurement. One is the improvement in nomenclature just referred to. The second is the use of names for the kinetic units of force. The British Association has sancticned the use of the name Dyne for the kinetic unit of force founded on the centimetre, gramme, and second, as units of length, mass, and time respecively. Prof. James Thomson has given the name Poundal for the British kinetic unit of force founded on the foot, pound, and second. The third help is the construction by Prof. Thomson, for the first time, so far as I know, of spring balances for indicating poundals and kilodynes. The fourth aid is Dr. Everett's admirable book on the C. G. S. system of units.

University of Glasgow, Feb. 7

\section{Seasonal Order of Colour in Flowers}

I AM very much obliged to $\mathrm{Mr}$. Buchan for his elaborate paper in NATURE, vol. xiii. p. 249, on the Flowering of Spring Plants (see my query, NAtuRE, vol. xiii. p. 129). Although agreeing with Mr. Pryor that the blue is anticipated by various other colours, yet $I$ think that the method of inquiry by averages is the only basis we can go upon; and that is the plan I have adopted for some time, I have now a carefully-assorted collection of hyacinths, and I see that the blue and white are coming out nearly together, the red showing as yet no colour whatever. What would be the action of light upon blue or red flowers, if the blue or red ray was carefully excluded, if this could be done? Would the flower thrive, and if so, would its colour be much altered?

Retford, Notts, Feb. 7

C. E. HERON ROGERS

\section{OUR ASTRONOMICAL COLUMN}

VARIAble Stars.--Herr Julius Schmidt publishes (in Astron. Nach., No. 2,074) the results of observations of variable stars made at Athens in 1875, amongst which the following may be noted :-

I. 34 Bootis, a star to which he had directed attention some years since, as certainly variable though observed with difficulty on account of proximity to $\epsilon$, was found to be at a maximum on April 26-a good determination. In 1872 he assigned a period of 369 days from six observed maxima, commencing $186 \%$, July $3 \mathrm{I}$, and as many minima, the first, 1867, November 18. Between the maxima of 1867 and 1875, we should have eight periods of about 353 days. The mean place of this star for the beginning of the present year is in R.A. I4h. $37 \mathrm{~m}$. 32s., N.P.D., $62^{\circ} 54^{\prime} \cdot \mathrm{r}$.

2. Mira Ceti. Three curves drawn from comparisons of this star with $a$ and $\gamma$ Ceti and $a$ Piscuim gave the date of maximum, February 27.5, March $\mathrm{I}$ and 3 respectively, of which the latter is preferred. Calculating from the formula of sines in Schönfeld's second catalogue, the maximum of 1875 is fixed to February $24^{\circ} 2$. Observed minimum, October 30.

3. $\eta$ Geminorum.-The variability of this star was detected by Schmidt in 1865, and has since been confirmed by Schönfeld, who found for the brighter phase small and not very regular fluctuations, but for the minima a regular diminution and increase, the first continuing about six weeks, and the last perhaps rather longer. This is in near agreement with Schmidt's previous deductions. $\mathrm{He}$ had found by comparison with $\mu$ Geminorum that $\eta$ at times remained constant for several months about the maxima, of which, writing in 1869 , he states he had been unable to assign the dates. In 1875, however, two maxima were noted, Feb. 25 and Sept. 23 ; showing an interval of 2 ro days. The period assigned in the last Manheim catalogue is $229^{\prime} \mathrm{I}$ days. This star is of a deep ycllow colour. Variation between extremes of 3.2 and $4: 2$.
4. $\epsilon$ Aurigæ.-Schmidt collects the results of his comparisons of the relative brightness of $\epsilon$ and $\eta$ Aurigæ, between the years $1843-1875$. The star is irregularly variable within somewhat narrow limits.

5. $u$ Herculis.-The principal period appears to be about 38.7 days, but according to Schmidt (A. N. 2,075) the curve exhibits waves of about twelve hours' duration, which are of the greatest depth at the principal minimum, and comparatively shallow at the maximum, and he has given a figure explanatory of what he considers to have been the law of variation between 1875 , July 4 , and Aug. 29. So unique a case appears to require further investigation.

6. g Herculis.-This reddish-yellow variable was discovered by Mr. Baxendell in 1857 , and has been carefully observed by Schmidt. The period, according to Schönfeld, has varied between 40 and 125 days, the star thus resembling in the great irregularity of period the wellknown R Scuti, which was discovered by Pigott in 1795 . Last year Schmidt's comparisons sbowed three maxima and two minima, indicating periods 77,73 , and 77 days. The variation extends through little over one magnitud?.

7. $a$ Cassiopex.-Of this star Schmidt remarks that the fluctuations of brightness in 1875 were not greater than in the cases of other stars, which are not yet placed upon the variable list.

8. T Coronæ Borealis (Nova 1866).-Mostly ninth magnitude, or ratber fainter; exhibiting sensible variation, but to very small amount.

9. $R$ Scuti.--Observed maxima on October 12 and December 8 give the short period of 57 days. The period entered in Schönfeld's second catalogue is $7 \mathrm{r} \cdot \mathrm{r}$ days. There are great irregularities in the case of this star, not only in the period but in the degree of bright ness at both maximum and minimum; the former has betn noted between 47 and $5 \%$, and the latter between 6.0 and 8.5 .

Minor Planets.-No. i 31 , Vala, discovered by Prof. Peters at Clinton, U.S., 1873, May 24, has so far been unsuccessfully sought at Pold and Berlin between limits of $-30 \mathrm{~m}$. and $+15 \mathrm{~m}$. in respect to the place of the ephemeris apparently founded on Stockwell's elements the longitude of perihelion in this orbit differs materially from that given by Knorre's earlier calculation, and possibly a misprint or error of transcription may be the cause of the difficulty.-Prof. Tietjen notifies that the ephemeris of No. I4I, Lumen, in the Berliner fahrbuch for 1878 , is vitiated by an error in Astr. Nach., No. 2,030, where $\omega$ is substituted for $\pi$; the habit of some computers of giving the orbital angle between perihelion and node, instead of the longitude of perihelion itself, is certainly not without its inconvenience, and this is more particularly the case with early orbits of comets.--No. 156 discovered by Palisa, 1875 , Nov. 22 , has been named Xanthippe. -New elements of No. 158 give a period of $\mathrm{I}, 889$ days, or $5^{\circ} \mathrm{I} 7$ years.

The Saturnian Satellite, Hyperion,- Observations of this faint object made with the 26 -inch refractor of the U.S. Naval Observatory on forty nights between 1875, June 16 and Nov. 25, appear in No. 2,076 of the Astron. Nach. It is stated that the observations were generally made with difficulty. Prof. Asaph Hall acknowledges his obligations to Mr. Marth for his ephemerides of the satellites of Saturn, by which he has endeavoured to facilitate identification of these objects, and which could only have been prepared at an expenditure of much time and trouble.

\section{THE DATE OF EASTER}

WE revert to this subject with the view to reproduce the arithmetical rule to find Easter Sunday in the Gregorian Calendar, which was first given by the 
eminent German mathematician and astronomer Gauss, in Zach's Monatliche Correspondenz, I800.

1. From 1800 to 1899 put $m=23, n=4$.

"I I900 to $2099, m=24, n=5$

2. Divide the given year by 19 , and call the remainder $a$.

3. $", \quad$ by $4, "$,

5. Add $" m$ to I 9 times $a$, divide the sum by 30 , and call

the remainder $\ldots \ldots \ldots$... $\quad \ldots \quad \ldots \quad d$.

6. Add together $n$, twice $b$, four times $c$, and six times $d$, divide the sum by 7 , and call the remainder $e$.

Then Easter Sunday is March $22+d+e$, or

$$
d+e-9 \text { of April. }
$$

To apply this rule to the present year, we have-

I. $m=23 \quad n=4$

2. For $\frac{1876}{19}$ remainder is 14 .

3. For $\frac{1876}{4}$ remainder is o

4. For $\frac{1876}{7}$ remainder is o

5. For $\frac{23+19 \times 14}{30}$ remainder is 19

6. For $\frac{4+0+0+6 \times 19}{7}$ remainder is 6 .

And Easter Sunday is March $22+19+6 \Rightarrow$ March 47 or April 16 ; or $19+6-9$ of April $=$ April 16 .

Note.--The following are the two exceptions to the above rule :-

I. If Easter Sunday is brought out April 26, we must take April 19.

2. If Easter Sunday results on April 25 by the rule, the I8th must be substituted when the given year, increased by one, and then divided by 19 , leaves a remainder greater than $\mathrm{I}$.

PROF. FLOWER'S HUNTERIAN LECTURES ON THE RELATION OF EXTINCT TOEXISTING MAMMALIA ${ }^{1}$

\section{II.}

THE extinct Marsupialia, Edentata, and Ungulata were treated of fully in the previous course. It is only proposed now briefly to recapitulate the principal results as bearing on the derivative hypothesis, and to call attention to some recent additions to our knowledge of the past history of these groups.

The Monotremata, represented only by the Ornithorhyncus and Echidna of Australia, the lowest and most reptilian of mammals, seem to be the survivors of a group of animals of intermediate structure through which the passage from the lower to the higher vertebrates was made. But of this palæontology has hitherto afforded not the slightest proof. Except some Pleistocene remains of one of the existing genera, no trace of any extinct animal allied to the Monotremata, or showing any decidedly intermediate characters between Mammals and the Sauropsida, has ever been found. The earliest known remains of mammals -in fact, all those of the Mesozoic period-appear to belong to the Marsupialia, although too little is yet known of their general organisation to pronounce definitely on their affinities. As early as the time of deposition of the Purbeck beds, below the Wealden, two very distinct types of dentition prevailed, bearing some resemblance to those characterising the modern polyprotodont and diprotodont types, the one being mainly carnivorous

I Abstract of a course of lectures delivered at the Royal College of Surgeons "On the Relation of Extinct to Existing Mammalia, with Special Reference to the Derivaive Hypothesis," in conclusion of the course of 1873 . (See Reports in NATURE for that year.) Continued from p. 308 .

I See Abstracts in NATURE, 1873 . or insectivorous, and the other frugivorous or herbivorous. True Marsupials, allied to the American Opossums, have been found in the Eocene and Lower Miocene formations of Europe, but not later. Many of the recently discovered insectivorous and carnivorous mammals of the North American Eocenes also appear to have been Mar. supials, but the Tertiaries of no part of the world, except the Australian Pleistocenes, have yielded forms allied to the Wombats, Kangaroos, and Phalangers, now so characteristic of the fauna of that land.

Palæontology teaches scarcely anything of the past history of the Edentata, an order which might be supposed from the diversity in structure and geographical distribution of the animals now included in it to have occupied a conspicuous position formerly in the fauna of the world. The American gigantic Pleistocene forms, the Megatherium, Glyptodon, and their allies, are of great interest, but they are all closely related to the existing species of the same countries, and their prosenitors have hitherto been sought in vain in the earlier formations of the country. Apparently they formed no part of the Eocene or Miocene fauna of the northern part of the Continent. The European Miocene Edentates, Macrotherium and Ancylotherium, appear to be more related to the existing Old World forms, but their structure is as yet very imperfectly known.

The difference between the Perissodactyle and Artiodactyle Ungulates was fully established in the earliest tertiaries, beyond which we are not able to trace their history. Recent researches of Leidy, Cope, and Marsh have enabled us to form a tolerably connected idea of the history of both these groups in North America. Before 1869 not a single Eocene Perissodactyle had been discovered in that country; it is now known that while the Lophiodons and Palceotheriums flourished in the Old World, similar forms ranged through the sub-tropical forests of the regions in which the stupendous mountain ranges of Western North America have since been elevated. None of these appear to be identical specifically with the European forms, and even the generic indications, being often founded only on very limited portions of the organisation, as a few teeth, must be regarded as provisional. The best known forms, Hyrachyus and Palaosyops, are respectively Lophiodontoid and Palæotheroid. Some are allied to the Hyracotherium, one of which, Orohippus, seems to connect that form directly with Anchitherium. One form only, Diceratherium, is Rhinocerotic; it is found in the uppermost Eocene strata of Utah, and gives the earliest indications of this group yet known. It seems to be connected with the lower Eocene Hyrachyus on the one hand, and the Miocene Hyracodon on the other. In the Miocene period, the Perissodactyles attained a great development of form and size, and the groups became more differentiated, and some of them highly specialised. True tapirs do not seem yet to have been met with. The Palæotheroid and Lophiodont forms had nearly, if not quite, died out, but the more horse-like Anchitherium was abundant, and appears to have continued the line from the Eocene Orohippus (which had four toes on the fore foot) to the true horses of the Pliocene period. Rhinocerotic forms now became ascendant, being represented by Dicerotherium with a pair of lateral horns on the nasal bones, Hyracodon, a very generalised hornless Rhinoceros, with the complete number of incisor and canine teeth, and several species assigned to the European genus Aceratherium. But the most remarkable of the Miocene Perissodactyles of North America are a number of species of gigantic size, to the first known of which Leidy, in 1853, gave the name of Titanotherium, and of which other, or perhaps the same, forms have been named by Marsh Brontotherium, and by Cope Symborodon. Their head was large and much elongated, as in the rhinoceros; but they had a pair of stout diverging osseous protuberances like horn cores on the nasals or anterior part of 